\title{
Determinants of hygienic handling of food by consumers in the COVID-19 pandemic context: A cross-sectional study in Vietnam
}

\author{
Huy Duc DANG ${ }^{*}$ (D), Au Hai Thi DAM ${ }^{2}$
}

\begin{abstract}
The objectives of this research are trifold. The first is to unveil antecedents of food-handling behaviors in the context of the COVID-19 pandemic. The second is to investigate the consistency of impacts of proposed determinants across different handling behaviors. The third is to confirm whether or not the premise of intention as the sole direct determinant of behavior in the Theory of Planned Behavior (TPB) holds. As such, TPB served as the guiding theory, and Factor Analysis and Seemingly Unrelated Regression were used for data analysis. The results discuss the discrepancy of impacts between heterogeneous foodhandling behaviors. The contribution of habit and information-seeking behavior across behaviors were confirmed, while the influence of income, minor, objective norm, perception of food risks, trust, perceived behavioral control, and intention was statistically significant but inconsistently differed between behaviors. The independent contributions of gender, age, education, subjective norm, and attitude were negligible. This paper's findings offer evidence to highlight the role of volitional predictors to anticipate safe food-handling behaviors to suggest suitable policy interventions to reinforce the last line of heath defense in the household, especially in the context of the COVID-19 pandemic.
\end{abstract}

Keywords: COVID-19 pandemic; theory of planned behavior; food-handling behavior; habit; information-seeking behavior.

Practical Application: Provide suggestions to promote safe food handling in the COVID-19 context.

\section{Introduction}

The recent COVID-19 outbreak has affected all aspects of life. Ever since, the disease continues to spread all over the territory of Vietnam due to the non-stop returning of the Vietnamese overseas to seek safe shelter against the pandemic, which has gone more severe and overwhelming worldwide. Despite no clear evidence, experts suspect that the zoonotic SARS-CoV-2 has been transferred from the animal host to human and mutated from the nonpathogenic- to the pathogenic form (Andersen et al., 2020). Moreover, the virus has been discovered to be able to last on various surfaces for up to 72 hours (van Doremalen et al., 2020), which could create the threat of cross-infection due to the consumption preference of fresh foods, unsafe food processing in household food preparation context (Dang-Xuan et al., 2018), and transportation malpractices of food (Nguyen et al., 2015). Given the past experience with the outbreak of the Avian Influenza in 2008, risky behaviors also included preparing the infected poultry before consumption (Figuié \& Fournier, 2008). For that reason, animal diseases have heightened consumers' anxiety regarding food peril, and subsequently, their behavioral changes to mitigate foodborne disease (Figuié \& Fournier, 2008; Han \& Choi, 2018; Dang \& Tran, 2020a), which could also be the case of COVID-19.

Most foodborne illness cases were advocated in the context of home because of risky eating behavior (Scott, 2003). However, consumers seem to trivialize the risk of contracting foodborne diseases at home than other sources (Nesbitt et al., 2014).
With the growing number of foodborne incidence worldwide, the home remains the household's last line of defense against foodborne diseases (Scott, 2003; Teisl et al., 2016). Therefore, the importance of at-home food handling and preparing is beyond dispute. Between 1994 and 2016, related literature employed various behavioral-change theories to explain distinct safe food-handling behaviors, including the Health Action Process Approach (HAPA), the Health Belief Model (HBM), the Theory of Planned Behavior (TPB), and the Theory of Reasoned Action (TRA) (Young et al., 2017a). Among those, TPB has been found to outperform other models in terms of greater variance explained to be the most commonly applied theory (Mullan et al., 2015; Young et al., 2017a, b, 2018), which explains why we chose TPB as the theoretical foundation of this study. From 66 pertinent studies, the meta-analysis of Young et al. (2017b) further identified important determinants of safe foodhandling behaviors across studies, namely knowledge, attitudes, risk perceptions, habits, subjective norm, self-confidence and control, and intention (see also Gstraunthaler \& Day, 2008; Mullan et al., 2015; Young \& Waddell, 2016). However, the inconsistent impacts of the mentioned predictors were confirmed on different food-handling behaviors - adequate cooking, avoiding consumption of risky foods, cross-contamination/hygiene, and time-temperature controlling. Furthermore, most of the related studies reviewed focused solely on distinct behaviors that potentially raise the biased toward a specific behavior and 
inappropriate to generalize for other behaviors. Additionally, as most studies investigate the role of subjective knowledge, the impact of objective knowledge is left unanswered. Based on the inherent discrepancy between subjective- and objective knowledge (Tiozzo et al., 2019), and the confirmed contribution of subjective knowledge, this study contends that objective knowledge may also explain safe food-handling behaviors. In the COVID-19 setting, it is also reasonable to argue that the presence of a highrisk minor in the family possibly influences and mandates the practice of safe behaviors (Scott, 2003; Young \& Waddell, 2016; Dang et al., 2019). Besides, trust - an important predictor explaining perceptions and behaviors changes regarding safe foods in the context of food chaos in Vietnam (Ifft et al., 2009; Dang et al., 2019; Dang \& Tran, 2020b) and other food-related decision-making behaviors (e.g., food purchase), remains absent in past food-handling behaviors' studies. City inhabitants seem to trust their frequent and acquainted retailers in the wet market despite acknowledging that the best and safest poultry is sold in supermarkets (Figuié \& Fournier, 2008), which make it reasonable to hypothesize that trust in the information given by a reliable source could incite safe food-handling practices.

In light of the nature of the novel Coronavirus, a recent study within a controlled lab setting found that the virus could remain stable on various kinds of surfaces for up to 72 hours, depending on the material (van Doremalen et al., 2020). The zoonotic nature of the virus and the preference of the Vietnamese for fresh foods, which are usually prepared and shipped overnight (Nguyen et al., 2015; Dang et al., 2019), could create a potential condition predispose end consumers to get infected by Sars-Cov-2 in case of wrong handling of foods. For that reason, risk perceptions deemed important in influencing safe food-handling; low-risk perceptions correspond to unsafe handling (Clayton et al., 2002; Bearth et al., 2014). Perception of food risks is examined to assess whether personal judgment about the unknown may influence safe food-handling behaviors. Besides, how consumers respond to health emergencies (i.e., COVID-19) and their awareness of hazard prevention could be influenced by the food safety information received (Kuttschreuter et al., 2014); thus the frequent information-seeking behavior can enhance and induce them to take actions against food risks (if any) more promptly. It is also be noted that the socio-demographic characteristics of the consumers have been associated with safe food-handling behaviors (Nesbitt et al., 2014). Based on the above studies review, the author hypothesizes that additional variables could affect handling behaviors and set out to test that in the COVID-19 context. The unique contribution of this investigation is that it applies significant predictors reviewed to date and additional supplements to explain simultaneously the four most commonly studied behaviors of safe food-handling, including adequate cooking of foods, avoiding consumption of risky foods, preventing cross-contamination/practice personal hygiene and time-temperature controlling of foods, especially in the context of the outbreak of the COVID-19 pandemic. Furthermore, this study enlightens knowledge in the case of Vietnam - a transitioning economy in South East Asia, where this specific contribution is pauce in the current body of literature.

\section{Aims of the study}

The aim of this paper was to apply an extended TPB model in an attempt to grasp simultaneously four most common safe food-handling behaviors of the consumers in their kitchens during the outbreak of COVID-19. In specific, we employed additional variables namely subjective/objective knowledge, perception of food risks, trust, habit, information-seeking behavior, and sociodemographic characteristics (i.e. gender, age, edu, income, and minor) to explain the uptake of four distinct safe food-handling behaviors in order to discern:

1. Whether these predictors would explain a larger variance of the behavior over the standard TPB;

2. Whether the impacts of these additional variables contribute differently to explain different behaviors;

3. Whether the premise of intention as the only direct determinant of behavior (in the original TPB) holds.

\section{Literature review and empirical framework}

The behavioral-change theories have been ubiquitously adopted as an effective way to explain and predict the (un)safefood handling behaviors at home. Among those, the Theory of Planned Behavior (TPB) is identified as the most common applied theory (Young et al., 2017a,b, 2018), which appears to explain the most variance in safe food-handling behaviors (Mullan et al., 2015). The systematic reviews of Young et al. (2017a, 2018) show that other theories of behavior-change (e.g., Protection Motivation Theory - PMT, Health Belief Model HBM) also explain a certain proportion of behavioral intentions and self-reported/observed behaviors. Furthermore, they look into the $\mathrm{R}^{2}$ of different significant variables and finally come to suggest that the flexible use of theories composed of appropriate significant variables would help to guide the development of a successful safe-food handling behavioral model. In spite of biased outcomes of studies, the meta-analyses of Young et al. (2017b) suggests that the significant impact of attitudes, risk perceptions, habits, subjective norm, self-confidence, and control on safe food handling behaviors are consistent across researches and should be incorporated into an appropriate theory of behavior-change in future studies. This paper decides to depart from the basis of the TPB as the back-bone theory, which consists of the most valuable determinants significant to the success of the research as suggested in the mentioned research.

The fundamental reviewed TPB model consists of five exogenous variables, including knowledge, habit, subjective norm, perceived behavioral control, and intention (Young et al., 2017a,b, 2019). Researchers often employ knowledge as the most commonly studied behavioral driver (Young et al., 2017b, 2019). During the outbreak of Avian influenza, knowledge is found associated with consumers' behavioral changes; surprisingly, the more knowledge consumer possessed, the less of their chances for behavioral changes (Gstraunthaler \& Day, 2008). The impact of knowledge on behavior seems consistent across studies (Young et al., 2019). However, it should be noted that knowledge increase does not always translate into positive behavioral change (Clayton et al., 2002). Nevertheless, older 
people with low food-handling knowledge may have riskier foodhandling behaviors (Almanza et al., 2007; De Jonge et al., 2010; Murray et al., 2017). Also, handlers' knowledge varies depending on their age, gender, and food-risk types (Santos et al., 2008; Murray et al., 2017). Most literature included these studies are in favor of self-reported knowledge (or subjective knowledge), while Tiozzo et al. (2019) found a mismatch between subjective and objective knowledge. Indeed, the impact could be different as people tend to overestimate their subjective knowledge, which makes them feel at ease (Tiozzo et al., 2017). For that reason, this study investigates the impact of both subjective and objective knowledge on food-handling behaviors. The systematic review of Young et al. (2017a) found that habit and perceived behavioral control were consistent and significant predictors of shoppers' overall safe food handling behavior. The strong and unanimous linkage between these constructs with safe food handling behavior was confirmed in the additional systematic review and meta-analysis (Young et al., 2017b). Food handlers' habits are of importance in determining safe food handling behaviors because for many people, safe food handling is likely a repetitive, unconscious, and routine activity influenced by past experiences (Mullan et al., 2015; Young \& Waddell, 2016), which needs not be triggered by conscious intentions. If habits are an extended component of the TPB, perceived behavioral control and subjective norm, along with attitude, are solid key determinants of behavior in the original TPB (Ajzen, 1991), which have shown to explain two-thirds of the variance in intention to adopt safe food-handling behaviors, although poorly construe the variance of different behaviors (Mullan et al., 2015).

Safe food-handling behaviors can be referred to as risk management behaviors of defending the household against food risks. For that reason, these risk-mitigating behaviors also fall under the scope of risk theories. Developed in the 1970s, the psychometric paradigm has progressed from its original postulation of the relationship between the expected probabilities and the outcomes of unfavorable events (Fischhoff et al., 1978; Slovic, 1992). It is further oriented toward the concept of personal subjective evaluation such as fears and expectations about unwanted corollary of given activities or events (Lo \& Chan, 2017). Thus, the psychometric scales take into account risk perceptions from a dreadful sense of risks that are severe or uncontrollable and from risks that are unknown and unfamiliar (Slovic, 1992). In light of the 72-hour surviving of the novel Coronavirus (van Doremalen et al., 2020), its zoonotic nature, and the fresh food preference of Vietnamese consumers (Nguyen et al., 2015; Dang et al., 2019), wrong handling of foods could lead to cross-infection. Thus, we also investigate the perception of food risks to evaluate if personal judgment over the unknown could influence safe food-handling behaviors. Besides, consumers' response to health issues (i.e., Sars-Cov-2) and their potential risk prevention could be subject to the food safety information received (Kuttschreuter et al., 2014). Hence, corresponding to the safe food-handling information received, we hypothesize that active information-seeking behavior could also contribute to the implication of safe food-handling behaviors. Previous literature has shown that trust also accounts for alterations in the information sources to address concerns with food risks as well as in the information-seeking behaviors
(Tiozzo et al., 2019). Studying the intentions toward safe foods, Spence et al. (2018) found that trust replaced subjective norm as the second most important determinant in the extended TPB to explain behavioral beliefs. It is reasonable to expect a gap between intention and real behavior because the intention often explains less than $50 \%$ of the variance in actual behaviors (Young et al., 2017b). In other words, what people think they do might be substantially dissimilar from their actual actions. Previous literature has granted evidence on the correlation between trust and consumers' behaviors. During the Avian influenza outbreak in 2009, low trust was reported to give way to the abandonment of governmental certified products (Ifft et al., 2009). Dang et al. (2019) contended that trust associates with customers' uptake of certified traceable foods in Vietnam's detrimental food context. Hence, the author reasonably expects that trust also plays a positive role in determining handling behaviors. Furthermore, various sociodemographic determinants (e.g., gender, age, education, income) have been discovered to be drivers of safe food-handling behaviors among food handlers (Young et al., 2017b). The high-risk health status of family members of food handlers is also included in this study, as previous research has provided evidence that having a high-risk family member might encourage the practice of safe food-handling (Scott, 2003; Young \& Waddell, 2016).

\section{Materials and methods}

\subsection{Participants}

This cross-sectional study analyzed data referring to various safe-food handling behaviors during the outbreak of COVID-19 disease gathered through an online survey by Google Form to avoid duplication. Back translation was used to compose the questionnaire in English and translate it into Vietnamese. The survey was conducted in February 2020, right after the first 16 infected patients were declared making a full recovery. The research sample consisted of household members responsible for handling food products. The participants' responses were randomly collected online. The survey was first launched and shared on various groups and fan pages on Facebook with foodrelated interests. Unfortunately, the response rate was much lower than expected. We later pivoted into the snowball method and achieved great consequences. Obviously, the respondents found it more confident to express their ideas with an acquaintance rather than a stranger. Participants who were not the main food handlers of the family were excluded. Missing values were not possible thanks to the mandatory mode of Google Form for each question. A total of 167 valid observations were entered into the data analysis.

\subsection{The questionnaire}

A questionnaire with 16 items was developed basing on the extensive review of the existing literature (RodríguezEntrena et al., 2016; Young et al., 2017b; Spence et al., 2018; Dang et al., 2019; Tiozzo et al., 2019). A pilot test was carried out to improve the questionnaire's quality in terms of validity, word-used appropriateness, and soundness of the content. 
To accomplish the research purpose, the following topics were studied, as in this same order of structure in the questionnaire:

1. Socio-demographic characteristics.

2. Subjective and objective knowledge.

3. Perception of food risks.

4. Level of trust in different authorities considered being information sources.

5. Information-seeking behavior.

6. Safe-food handling habits.

7. Subjective norms.

8. Perceived behavioral control.

9. Attitude

10. Behavioral intention.

11. Self-reported behaviors.

Table 1 reports the detailed content of the questionnaire and measurements for constructs with corresponding references, and Table 2 illustrates the descriptive statistics of the studied sample.

Following Tiozzo et al. (2019), the objective knowledge was measured using seven true/false food-safety-related questions (see Table 1). The variable was then ranked among poor ( $0-2$ correct answers), medium (3-5 correct answers), and good (6-7 correct answers). To investigate respondents' subjective knowledge, a self-reported Likert-type scale of 10 scores ranging from 1 'poor' to 10 'excellent' was used. The variable was then similarly classified into three groups ranging from poor (between 1-5), medium (between 6-7), and good (between 8-10). For food risk classification purposes, the perception of food risks was taken as a vehicle using an analogous Likert-type scale of 10 ranging from 1 'not at all exposed' to 10 'highly exposed.'

\subsection{Factor analysis}

For data reduction, the most popular method - principal component analysis (PCA) - was used. Before PCA, the intercorrelation among test items was measured using Cronbach's Alpha. In overall, the Cronbach's Alpha indicates acceptable internal consistency for investigated constructs namely Trust (0.960), Habit-AC (0.742), Habit-CC (0.615), Habit-TC (0.678), Habit-CR (0.885), Subj-norm (0.650), PBC (0.955), AT-AC (0.859), AT-CR (0.888), AT-CC (0.873), AT-TC (0.875), BE-AC (0.684), BE-CR (0.692), BE-CC (0.924), BE-TC (0.858). For factor loading analysis, the cut-off value of 0.5 was identified as an appropriate threshold to suppress the low-power items (Hair et al., 2010). Besides, KMO tests' outcomes were above 0.5 , and Barlett's tests were significant at $1 \%$. These metrics indicated that the studied data satisfied the factorable conditions for factor analysis (Hair et al., 2010). After the PCA procedure, all standardized factor scores were generated to be used in the subsequent analysis. The results of the PCA can be seen in Table 3. The factor analysis was done using SPSS version 24.0.

\subsection{Seemingly Unrelated Regression (SUR)}

The interconnectedness of safe food handling behaviors is obviously linked to the ultimate purpose of defending households against food risks. The correlation of residuals is further confirmed with the statistical results in Table 4.

Given that, it is more appropriate to investigate disparate safe food handling behaviors through a system of seemingly unrelated regression equations (or the SUR method) than using the OLS approach. The safe food handling behavioral model is a system of equations that can be estimated independently as shown:

$y_{i}=X_{i} \beta_{i}+\varepsilon_{i}, \quad i=1,2, \ldots, M$

where $y_{i}$ is ( $\mathrm{T} \mathrm{x} 1$ ) vector with elements $y_{t i} ; \varepsilon_{i}$ is the error terms assumed to have cross-equation correlations. $X_{i}$ is ( $\mathrm{T} \mathrm{x} K_{i}$ ) matrix whose columns represent the Tobservations on an explanatory variable in the $i^{\text {th }}$ equation; $\beta_{i}$ is a $\left(k_{i} \times 1\right)$ vector with elements $\beta_{i j}$

Finally, we can stack all the equations into an SUR model

$\left[\begin{array}{c}y_{1} \\ y_{2} \\ \vdots \\ y_{M}\end{array}\right]=\left[\begin{array}{cccc}X_{1} & 0 & \cdots & 0 \\ 0 & X_{2} & \cdots & 0 \\ \vdots & \vdots & \ddots & \vdots \\ 0 & 0 & \vdots & X_{M}\end{array}\right]\left[\begin{array}{c}\beta_{1} \\ \beta_{2} \\ \vdots \\ \beta_{M}\end{array}\right]+\left[\begin{array}{c}\varepsilon_{1} \\ \varepsilon_{2} \\ \vdots \\ \varepsilon_{M}\end{array}\right]$

All of the regression models were pre-tested for the basic assumptions of heteroskedasticity. The Breush-Pagen test indicated the presence of heteroskedasticity for adequate cooking (p-value $<0.05$ ), and consumption of RF. (p-value $<0.01$ ). For that reason, to avoid heteroskedasticity, we used the suest command incorporated the Huber/White sandwich covariance matrix estimators, vce (robust) option, which are also robust to another violation including the first-order autocorrelation. Indeed, all Durbin-Watson statistics for four models ranged from 1.5 to 2.5 (see Table 5), denoting that autocorrelation is not a problem. Furthermore, the problem of multicollinearity did not exist as all VIFs were less than 3 . The econometrics model is estimated by STATA version 14.1.

\section{Results}

\subsection{Predicting behaviors}

Adequate cooking of foods (ACF)

For the original TPB, none of the variables (PBC, subjective norm, attitude, intention) were significant predictors of the adequate cooking of foods, all p-value $>0.1$. The amount of variance accounted for was low and not significant: $R^{2}=0.058$, $\mathrm{F}(4,162)=1.47, \mathrm{p}=0.213, \mathrm{RMSE}=0.982$

For the extended TPB, the model explained $70.16 \%$ of the behavior of adequate cooking of foods, $\mathrm{F}(15,151)=31.28$, $\mathrm{p}<0.001, \mathrm{RMSE}=0.572$, with minor, $\beta=0.269, \mathrm{p}<0.05$, objknow, $\beta=-0.391, \mathrm{p}<0.01$, habit, $\beta=0.169, \mathrm{p}<0.001, \mathrm{PBC}, \beta=0.224$, $\mathrm{p}=0.001$, the rest was not significant, all $\mathrm{p}>0.1$. Overall, the extended TPB explained a significantly larger portion of the variance of the ACF behavior. The extended variables elucidate an extra cumulative rate of $64.34 \%$ of the variance of the 
Table 1. Variables designed in the questionnaire and available response options.

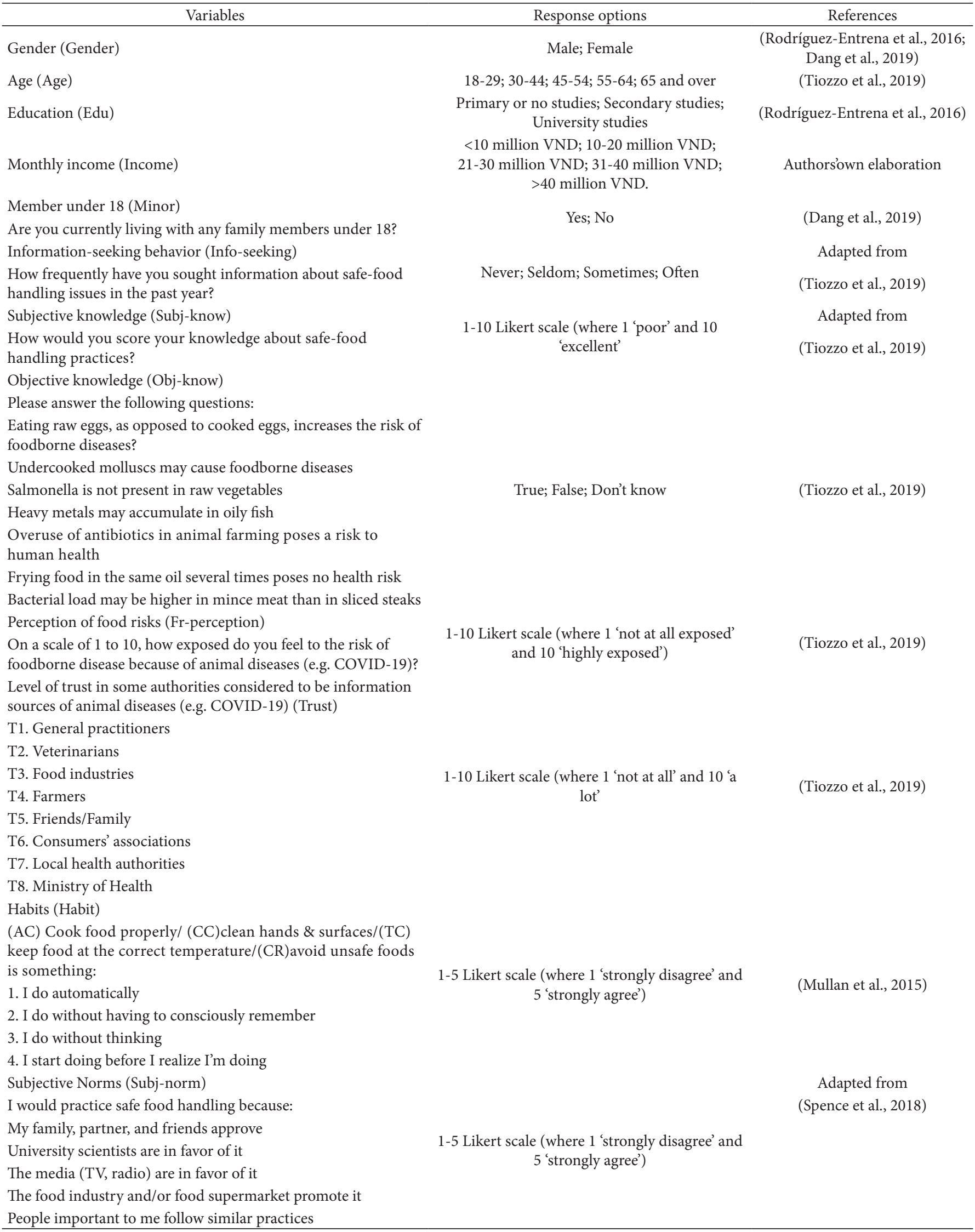


Table 1. Continued...

\begin{tabular}{l} 
Variables \\
\hline Perceived Behavioral Control (PBC) \\
During the outbreak of COVID-19 \\
PBC1. It is easy to practice safe food handling \\
PBC2. I am confident on my skills of safe food handling
\end{tabular}

PBC3. I am able to prepare food safely without help from others

PBC4. It is easy to understand which food handling is correct

PBC5. I am able to understand safe food handling without help from others

Attitude (AT)

For me, (AC) cooking food properly/ (CC) preventing crosscontamination/ (TC) keeping food at the correct temperature/ (CR) avoiding consumption of risky food would be:

1. Bad (1) - good (7)

2. Displeased (1) - pleased (7)

3. Foolish (1) - wise (7)

4. Harmful (1) - beneficial (7)

5. Unenjoyable (1) - enjoyable (7)

Behavioral intention (Intention)

Intentions and motivation to engage in safe food handling behavior in the future

Behaviors

Adequate cooking of foods (BE-AC)

AC1. Use of a thermometer to check cooking doneness

AC2. Achieving adequate cooking temperatures

AC3. Appropriate reheating of leftovers

Avoiding consumption of risky foods (BE-CR)

CR1. Avoiding consumption of unpasteurized milk, juices and cider, and raw sprout

CR2. Avoiding consumption of high-risk foods (e.g. raw meats, fish, seafood, eggs, non-dried deli meats without appropriate reheating...)

Prevent cross-contamination/practice personal hygiene (BE-CC)

CC1. Appropriate handwashing

CC2. Not handling food while ill

CC3. Washing fruits and vegetables

CC4. Not washing meat and poultry

CC5. Cleaning of kitchen surfaces, cutting boards, and utensils

CC6. Separating raw from cooked foods

Time-temperature control of foods (BE-TC)

TC1. Appropriate refrigeration, freezing, defrosting, and hot holding practices

TC2. Adherence to recommended storage times

TC3. Disposal of expired foods

\section{Response options}

References

Adapted from

(Spence et al., 2018)

1-5 Likert scale (where 1 'strongly disagree' and 5 'strongly agree')

1-5 Likert scale (where 1 'not likely' and 5 'very likely')

1-5 Likert scale (where 1 'strongly disagree' and 5 'strongly agree')

1-5 Likert scale (where 1 'strongly disagree' and 5 'strongly agree')

1-5 Likert scale (where 1 'strongly disagree' and 5 'strongly agree')
Adapted from

(Mullan et al., 2015; Spence et al., 2018)

Adapted from

(Young et al., 2017b)

(Young et al., 2017b)
1-5 Likert scale (where 1 'strongly disagree' and 5 'strongly agree')

Note: Variable names are in parentheses. 
Original Article

Dang; Dam

Table 2. Descriptive statistics.

\begin{tabular}{|c|c|c|c|c|c|}
\hline Variables $^{1}$ & Frequency (\%) & Mean & Std. Dev. & Min & Max \\
\hline \multicolumn{6}{|l|}{ Gender } \\
\hline Male & 23.95 & \multirow[t]{2}{*}{0.239} & \multirow[t]{2}{*}{0.428} & \multirow[t]{2}{*}{0} & \multirow[t]{2}{*}{1} \\
\hline Female & 76.05 & & & & \\
\hline \multicolumn{6}{|l|}{ Age } \\
\hline $18-29$ & 37.72 & \multirow{5}{*}{2.011} & \multirow{5}{*}{1.041} & \multirow{5}{*}{1} & \multirow{5}{*}{5} \\
\hline $30-44$ & 36.53 & & & & \\
\hline $45-54$ & 14.97 & & & & \\
\hline $55-64$ & 8.38 & & & & \\
\hline 65 and over & 2.40 & & & & \\
\hline \multicolumn{6}{|l|}{ Edu } \\
\hline Primary or no studies & 11.98 & \multirow{3}{*}{2.455} & \multirow{3}{*}{0.700} & \multirow{3}{*}{1} & \multirow{3}{*}{3} \\
\hline Secondary studies & 30.54 & & & & \\
\hline University studies & 57.49 & & & & \\
\hline \multicolumn{6}{|l|}{ Income } \\
\hline$<10$ million VND & 82.04 & \multirow{5}{*}{1.233} & \multirow{5}{*}{0.580} & & \\
\hline 10-20 million VND & 14.37 & & & 1 & 5 \\
\hline 21-30 million VND & 2.40 & & & 1 & $J$ \\
\hline 31-40 million VND & 0.60 & & & & \\
\hline$>40$ million VND. & 0.60 & & & & \\
\hline City & & & & & \\
\hline Ho Chi Minh City & 42.51 & 0.425 & 0.495 & 0 & 1 \\
\hline Otherwise & 57.49 & & & & \\
\hline Minor & & & & & \\
\hline Yes & 67.66 & 0.676 & 0.469 & 0 & 1 \\
\hline No & 32.34 & & & & \\
\hline Info-seeking & & & & & \\
\hline Never & 1.80 & & & & \\
\hline Seldom & 6.59 & 3.203 & 0.635 & 1 & 4 \\
\hline Sometimes & 61.08 & & & & \\
\hline Often & 30.54 & & & & \\
\hline Subj-know & & & & & \\
\hline Poor & 29.34 & & & , & 3 \\
\hline Medium & 50.30 & 1.910 & 0.701 & 1 & 3 \\
\hline Good & 20.36 & & & & \\
\hline Obj-know & & & & & \\
\hline Poor & 5.99 & 2023 & 0379 & 1 & 3 \\
\hline Medium & 85.63 & 2.023 & $0.3 / 9$ & 1 & 3 \\
\hline Good & 8.38 & & & & \\
\hline FFr-perception & & 7.778 & 2.031 & 1 & 10 \\
\hline Trust $^{2}$ & & $1.77 \mathrm{e}-07$ & 1 & -2.730 & 2.244 \\
\hline Habit-AC ${ }^{2}$ & & $2.40 \mathrm{e}-07$ & 0.999 & -3.526 & 2.156 \\
\hline Habit-CR ${ }^{2}$ & & $1.08 \mathrm{e}-06$ & 1 & -3.158 & 1.272 \\
\hline Habit-CC ${ }^{2}$ & & $7.80 \mathrm{e}-07$ & 1 & -5.320 & 1.532 \\
\hline Habit-TC ${ }^{2}$ & & $-4.90 \mathrm{e}-07$ & 0.999 & -5.631 & 1.275 \\
\hline Subj-norm ${ }^{2}$ & & $1.20 \mathrm{e}-07$ & 1 & -3.505 & 2.824 \\
\hline $\mathrm{PBC}^{2}$ & & $-1.27 \mathrm{e}-06$ & 1 & -1.771 & 2.848 \\
\hline AT-AC ${ }^{2}$ & & $-2.40 e-07$ & 0.999 & -3.653 & 1.163 \\
\hline AT-CR ${ }^{2}$ & & $-2.29 e-07$ & 0.999 & -3.121 & 1.251 \\
\hline AT-CC ${ }^{2}$ & & $4.80 \mathrm{e}-07$ & 1 & -3.313 & 1.182 \\
\hline AT-TC ${ }^{2}$ & & $7.71 \mathrm{e}-07$ & 1 & -3.470 & 1.162 \\
\hline Intention & & 4.179 & 0.506 & 2 & 5 \\
\hline $\mathrm{BE}-\mathrm{AC}^{2}$ & & $1.56 \mathrm{e}-06$ & 1 & -3.183 & 2.207 \\
\hline $\mathrm{BE}-\mathrm{CR}^{2}$ & & $-2.51 \mathrm{e}-06$ & 0.999 & -4.411 & 1.823 \\
\hline $\mathrm{BE}^{-\mathrm{CC}^{2}}$ & & $2.38 \mathrm{e}-07$ & 1 & -4.494 & 1.502 \\
\hline $\mathrm{BE}-\mathrm{TC}^{2}$ & & $6.71 \mathrm{e}-07$ & 0.999 & -5.141 & 2.001 \\
\hline
\end{tabular}

${ }^{1}$ Variable names are derived from Table $1 ;{ }^{2}$ The descriptive statistics of standardized variables after PCA. 
behavior; hence the prediction power of the extended TPB is better. This also casts doubt on intention as the only and direct determinant of behavior.

Table 3. Principle component analysis.

\begin{tabular}{lcccc}
\hline Constructs & Items & $\begin{array}{c}\text { Factor loading } \\
\text { range }\end{array}$ & $\begin{array}{c}\text { \% of } \\
\text { variance }\end{array}$ & Eigenvalues \\
\hline Trust & 8 & $0.760-0.940$ & 78.638 & 6.291 \\
Habit-AC & 4 & $0.629-0.837$ & 58.269 & 2.331 \\
Habit-CR & 4 & $0.846-0.887$ & 76.302 & 3.052 \\
Habit-CC & 4 & $0.659-0.709$ & 46.442 & 1.858 \\
Habit-TC & $3^{\text {a }}$ & $0.716-0.826$ & 61.011 & 1.830 \\
Subj-norm & 5 & $0.591-0.727$ & 43.019 & 2.151 \\
PBC & 5 & $0.871-0.955$ & 85.025 & 4.251 \\
AT-AC & 5 & $0.705-0.856$ & 65.101 & 3.255 \\
AT-CR & 5 & $0.754-0.887$ & 69.287 & 3.464 \\
AT-CC & 5 & $0.705-0.864$ & 67.532 & 3.377 \\
AT-TC & 5 & $0.679-0.863$ & 68.054 & 3.403 \\
BE-AC & 3 & $0.733-0.851$ & 62.648 & 1.879 \\
BE-CR & 2 & 0.874 & 76.469 & 1.529 \\
BE-CC & $4^{\mathrm{a}}$ & $0.852-0.937$ & 81.782 & 3.271 \\
BE-TC & 3 & $0.856-0.909$ & 78.664 & 2.360 \\
\hline
\end{tabular}

Note: All items are derived from Table $1 ;{ }^{\text {a }}$ Items Habit-TC4, BE-CC2, BE-CC4 are omitted due to lower than the cut-off value.

\section{Avoiding consumption of risky foods (ACRF)}

For the original TPB, PBC, attitude, intention were not significant predictors of avoiding consumption of risky foods with all $p$-value $>0.1$. Subjective norm was significant at $p$-value $<0.05, \beta=0.317$. The prediction power of the model was low, but significant: $\mathrm{R}^{2}=0.074, \mathrm{~F}(4,162)=1.98, \mathrm{p}=0.1, \mathrm{RMSE}=0.973$.

For the extended TPB, only the habit and info-seeking variables were significant, with habit, $\beta=0.772, \mathrm{p}<0.001$, info-seeking, $\beta=0.133, \mathrm{p}<0.1$. All extant variables were not significant, all $\mathrm{p}>0.1$. The amount of variance accounted for was fairly moderate and significant: $\mathrm{R}^{2}=0.655, \mathrm{~F}(15,151)=1.47$, $\mathrm{p}=0.213$, RMSE $=0.615$. The extended TPB's added variables explained an extra percentage of $58.13 \%$ of the variance of the ACRF behavior, thus demonstrating a stronger anticipating power. Also, the premise of intention as the sole predictor of behavior does not hold.

\section{Preventing cross-contamination/practice personal hygiene (PCC)}

For the original TPB, only intention $(\beta=1.183, \mathrm{p}<0.001)$ was the significant predictor of the PCC behavior. The model was able to explain $42.76 \%$ of variance of behavior, $\mathrm{F}(4,162)$ $=19.04, \mathrm{p}<0.001, \mathrm{RMSE}=0.765$. This indicates that intention remains the most powerful construct in explaining behavior.

Table 4. Correlation between residuals of safe food handling behaviors.

\begin{tabular}{lcccc}
\hline & Adequate cooking & Consumption of RF. & Cross-contamination & Temperature control \\
\hline Adequate cooking & 1 & & & \\
Consumption of RF. & $0.484^{* * *}$ & 1 & 1 & \\
Cross-contamination & $0.222^{* * *}$ & $0.187^{* *}$ & $0.863^{* *}$ & 1 \\
Temperature control & $0.235^{* * *}$ & $0.210^{* *}$ & & 1 \\
\hline
\end{tabular}

Asterisks ${ }^{* *},{ }^{* * *}$ report the levels of statistical significance at $5 \%$, and $1 \%$, respectively.

Table 5. The regression results of different food handling behaviors.

\begin{tabular}{|c|c|c|c|c|c|c|c|c|}
\hline \multirow{2}{*}{ Predictors } & \multicolumn{2}{|c|}{ Adequate cooking } & \multicolumn{2}{|c|}{ Consumption of RF. } & \multicolumn{2}{|c|}{ Cross-contamination } & \multicolumn{2}{|c|}{ Temperature control } \\
\hline & Coeff. & & Coeff. & & Coeff. & & Coeff. & \\
\hline Gender & $0.009(0.139)$ & & $0.190(0.133)$ & & $-0.167(0.144)$ & & $-0.204(0.137)$ & \\
\hline Age & $0.033(0.051)$ & & $0.029(0.039)$ & & $-0.009(0.054)$ & & $-0.004(0.054)$ & \\
\hline Edu & $-0.138(0.088)$ & & $-0.067(0.064)$ & & $-0.010(0.083)$ & & $-0.085(0.074)$ & \\
\hline Income & $-0.164(0.107)$ & & $-0.171(0.172)$ & & $0.211(0.093)$ & ** & $0.294(0.099)$ & $* * *$ \\
\hline Minor & $0.269(0.126)$ & $* *$ & $0.136(0.125)$ & & $-0.0003(0.124)$ & & $-0.020(0.143)$ & \\
\hline Subj-know & $0.005(0.070)$ & & $0.062(0.086)$ & & $-0.067(0.073)$ & & $0.061(0.090)$ & \\
\hline Obj-know & $-0.391(0.144)$ & $* * *$ & $0.069(0.166)$ & & $-0.056(0.147)$ & & $-0.038(0.208)$ & \\
\hline Fr-perception & $0.052(0.034)$ & & $0.036(0.031)$ & & $-0.017(0.032)$ & & $0.070(0.034)$ & $* *$ \\
\hline Trust & $0.103(0.063)$ & & $0.040(0.069)$ & & $0.145(0.070)$ & $* *$ & $0.160(0.077)$ & $* *$ \\
\hline Habit & $0.647(0.063)$ & $* * *$ & $0.772(0.085)$ & $* * *$ & $0.397(0.079)$ & $* * *$ & $0.097(0.050)$ & $* *$ \\
\hline Info-seeking & $-0.033(0.066)$ & & $0.133(0.081)$ & * & $0.191(0.075)$ & $* *$ & $0.272(0.069)$ & $* * *$ \\
\hline Subj-norm & $0.033(0.069)$ & & $0.038(0.071)$ & & $0.014(0.072)$ & & $0.079(0.078)$ & \\
\hline $\mathrm{PBC}$ & $0.224(0.065)$ & $* * *$ & $0.085(0.082)$ & & $-0.006(0.076)$ & & $-0.033(0.090)$ & \\
\hline Attitude & $-0.051(0.039)$ & & $0.004(0.050)$ & & $0.031(0.050)$ & & $0.073(0.051)$ & \\
\hline Intention & $0.046(0.122)$ & & $-0.040(0.180)$ & & $0.709(0.208)$ & $* * *$ & $0.909(0.175)$ & $* * *$ \\
\hline Cons. & $0.470(0.766)$ & & $-0.194(0.967)$ & & $-2.763(1.027)$ & $* * *$ & $-4.468(0.851)$ & $* * *$ \\
\hline \# of obs. & 167 & & 167 & & 167 & & 167 & \\
\hline $\mathrm{R}^{2}$ & 0.701 & & 0.655 & & 0.627 & & 0.617 & \\
\hline RMSE & 0.572 & & 0.615 & & 0.640 & & 0.648 & \\
\hline Durbin-Watson & 2.167 & & 2.090 & & 1.888 & & 2.192 & \\
\hline
\end{tabular}

\footnotetext{
Note: Robust standard errors are in parentheses. RMSE: Root Mean Square Error ${ }^{\star},{ }^{* *},{ }^{* * *}$ report the levels of statistical significance at $10 \%, 5 \%$, and $1 \%$, respectively.
} 
For the extended TPB, income $(\beta=0.211, \mathrm{p}<0.05)$, trust $(\beta=0.145, \mathrm{p}<0.05)$, habit $(\beta=0.397, \mathrm{p}<0.001)$, info-seeking $(\beta=0.191, \mathrm{p}<0.05)$, and intention $(\beta=0.709, \mathrm{p}<0.001)$ variables were significant construct predicting the variance of PCC behavior. The extended TPB with added variables was able to explain significantly better percentage of the behavior: $R^{2}=0.627$, $\mathrm{F}(15,151)=18.8, \mathrm{p}=0.000, \mathrm{RMSE}=0.640$. The model was capable of explaining an extra percentage of $21.3 \%$ of the PCC behavior compared to the original TPB. This corroborated that added variables were useful alongside the intention which alone already contributed to explain a high percentage of the behavior.

\section{Time-temperature control of foods (TCF)}

For the original TPB, the included variables of PBC, subjective norm, attitude, and intention accounted for $48.68 \%$ of the model, $\mathrm{F}(4,162)=17.08, \mathrm{p}<0.001$, RMSE $=0.725$, with subjective norm, $\beta=0.169, \mathrm{p}<0.1$, attitude, $\beta=0.093$, $\mathrm{p}<0.1$, intention, $\beta=1.140, \mathrm{p}<0.001$, but not $\mathrm{PBC}, \mathrm{p}>0.1$, making significant contribution to the model.

For the extended TPB, the anticipation power of the model was moderate, and significant: $\mathrm{R}^{2}=0.617, \mathrm{~F}(15,151)=12.45$, $\mathrm{p}<0.001, \mathrm{RMSE}=0.648$, with the magnitude of impacts went in a decreasing order of intention, $\beta=0.909, \mathrm{p}<0.001$, income, $\beta=0.294, \mathrm{p}<0.01$, info-seeking, $\beta=0.272, \mathrm{p}<0.001$, trust, $\beta=0.160, \mathrm{p}<0.05$, habit, $\beta=0.097, \mathrm{p}<0.1$, fr-perception, $\beta=0.070$, $\mathrm{p}<0.05$, neither of the remaining variables was significant, all $p>0.1$. An extra percentage of $13.07 \%$ of the variance of TCF behavior was explained by the extended TPB against the original one, indicating a valuable contribution of the added predictors in gaining the prediction power of the model. Furthermore, intention, in this case, was confirmed not the sole significant predictor of behavior.

Overall, the regression results indicate a discrepancy between impacts of explanatory variables across different handling behaviors.

\section{Discussions}

The first purpose of this research was to investigate whether the extended TPB, including gender, age, edu, income, minor, subjective knowledge, objective knowledge, perceptions of food risks, trust, habit, and information-seeking behavior, could explain a larger variance of the four behaviors: adequate cooking of foods, avoiding consumption of risky foods, prevent cross-contamination/ practice personal hygiene, time-temperature controlling of foods. The extended TPB anticipated approximately between 61 and 70 percent of the variance for all four behaviors. The previous articles using the TPB found that the performance of the model was relatively low (3-9\%) on stated behaviors (Mullan et al., 2015) and inconsistent across studies (Young et al., 2017b) in explaining the actual food hygiene behaviors, indicating the importance of the studied context (Young et al., 2018). This study further confirmed that the explanation power of the original TPB varied greatly across distinct behaviors. While the percentage of variance explained for the performance of adequate cooking of foods and avoiding consumption of risky foods was low (5.82 and 7.45\%, respectively), the TPB was able to elucidate much greater variance for the performance of preventing cross-contamination/practice personal hygiene and time-temperature control of foods at 42.76 and $48.68 \%$, respectively. The discrepancy between findings might presumably come from disparate measurements of behaviors (general versus specific behaviors). More importantly, the extended TPB outperformed the original one in explaining the four mentioned behaviors of ACF, ACRF, PCC, and TCF at the corresponding percentages of 70.16, 65.58, 62.71, and 61.75.

To address the second aim of the paper, the regression results revealed that the signs of impacts of significant predictors were considerably consistent across various behaviors. The habit was found to be the most consistent determinant of all four behaviors. The meta-analysis of Young et al. (2017b) reported that habit showed a stronger bond with behaviors than intentions. Indeed, this research provides evidence that habit is a potential determinant to bridge the intention-behavior gap, which the TPB fails to solve. Similar to the findings of Mullan et al. (2015); Young \& Waddell (2016), given the consistent context of the kitchen, it is likely that safe food-handling behaviors are reasonably derived from repetitive routines, which are volitional rather than intentional. For that reason, the more (good) behaviors are being practiced, the more habitual they might become, suggesting that once habitual, behaviors need not be entirely contingent on intentional motivation.

Regarding knowledge, empirical studies found that low food-handling knowledge associates with risky food-handling behavior (Bamgboje-Ayodele et al., 2019; Ncube et al., 2020). On the opposite, food handlers with good food safety knowledge would agree on the necessity of adhering to food safety measures while preparing foods to eliminate the risk of foodborne diseases (FBD) (Ruby et al., 2019). Surprisingly, while this study found that subjective knowledge was not significant across behaviors, objective knowledge was negatively associated with the behavior of adequate cooking of foods, and not statistically significant to any other behaviors. The underlying reason may derive from food handlers' age and risk status. As most food handlers in this study were not-very-old, age 18-44 (74.25\%), they could be at a lower risk of harm than much older people; thus, notvery-old people would express worse food-handling behaviors due to their positive views of safe foods (Bearth et al., 2014; Teisl et al., 2016), as opposed to the less assertive views of their older counterparts (De Jonge et al., 2010). It should be noted that knowledge increase does not always translate into positive behavioral change (Clayton et al., 2002), and handlers' knowledge varies depending on their age, gender, and food-risk types (Santos et al., 2008; Murray et al., 2017). Additionally, there may be a meager sign of over-confidence as $19.16 \%$ of food handlers possess less knowledge than they think they are, which potentially deviates them from best practices concerning safe food (Bamgboje-Ayodele et al., 2019).

Given the context of food chaos in Vietnam (Dang et al., 2019; Dang \& Tran, 2020a) and amid the outbreaks of both the African Swine Fever (ASF) and the COVID-19, it is reasonable that the majority of food-handlers (85.02\%) gave the score of six and above to the probability of being exposed to FBD due to animal diseases. This is in line with the fact that animal diseases would heighten consumers' concerns about food hazards (Han \& Choi, 2018). Once the perceived risks are high, corresponding prevention 
behaviors will be enabled (Bearth et al., 2014). However, the author found that risk perception does not necessarily translate into consistent behaviors; the positive impact of perceptions of food risks was found only on the behavior of time-temperature control of foods. A plausible explanation is that more heed might be paid toward more controllable, comfortable, and acceptable behaviors. The mean statistics of all items measuring the behavior of time-temperature control of foods were consistently above four (4.1-4.2), while the mean scores of items measuring other behaviors vary, including adequate cooking of foods (3.5-3.8), avoiding consumption of risky foods (3.7-3.8), and prevent cross-contamination/practice personal hygiene (2.3-4.3). For example, not washing meat and poultry before cooking is recommended by USDA to prevent cross-contamination (United States Department of Agriculture, 2013); however, the Vietnamese food handlers seem to disagree with this insight by giving the average point of 2.3 , which potentially be rooted in the false sense of the traditional practice of washing meat to remove the bacteria on the surface. Similarly, handlers' false perception of washing utensils (i.e., knife and cutting board) between handling both raw and cooked food could lower their risks actually increases the risk of contracting salmonella (DangXuan et al., 2018). Thus, it is possible to contend that the role of risk perception could also be dependant on the influence of other variables, such as habit and knowledge.

Consumers' capability to explicate and take actions against food hazards can be traced to the amount of information received regarding food safety (Kuttschreuter et al., 2014). Although finite studies investigate the behavior of actively seeking safe foodhandling issues, the empirical literature has confirmed the effects of the availability of information and FBD experience on food hygiene practices (Gstraunthaler \& Day, 2008; Ruby et al., 2019), which can be obtained by the intentional search of information. The information-seeking behavior would likely contribute to food handlers' awareness of food risks, which results in their readiness to take measures against discovered food hazards, even when they are far from experiencing the potential health risks. In a previous study, the awareness about the outbreak of Japanese bovine spongiform encephalopathy (BSE), also known as mad cow disease, reported by mass media, urges South Korean consumers to avoid possible health risks caused by the disease outbreak, even though they did not undergo any BSE events in South Korea (Han \& Choi, 2018). Information-seeking behavior was the second most consistent predictor across behaviors, except for adequate cooking of foods. Its positive impact denotes that the more food handlers search for food-handling information, the more likely they will practice safe food-handling in their kitchen.

Amid the outbreak of COVID-19 and the current problematic food context in Vietnam, it is potential that food handlers' cautious behaviors might be triggered by negative information. It is worth noting that the information received does affect people's trust in public authorities accountable for food safety management (Tiozzo et al., 2019). Past studies have revealed low trust among consumers in governmental agencies due to their ineffective intervention to stop unsafe food-related events (Ifft et al., 2009; Nguyen et al., 2015; Dang et al., 2019). One of the reasons was the lack of proper resources (e.g., inspection staff) (Nguyen et al., 2015). On the opposite, this study found the magnitude of trust placed on some authorities in the decreasing order of Ministry of Health (7.74), local health authorities (6.74), general practitioners (6.35), consumers' association (6.08), food industries (5.88), veterinarians (5.73), friends/family (5.00), and farmers (4.43), according to the mean statistics of trust items. The positive trust in governmental agencies (i.e., Ministry of Health, local health authorities) would be due to their in-time and thorough intervention against the COVID-19 outbreak. Moreover, transparent and pro-active moves against the disease outbreak are updated constantly to the public on time through orthodox media, which could help to regain and enhance public trust. The impacts of trust in this study are consistent with the findings of Figuié \& Fournier (2008) that Avian Influenza's risk fret could be ameliorated by confidence in the information and recommendations given by the government.

Besides the conventional and extended set of predictors of the TPB, experts commonly agree on the significant effects of socio-demographic characteristics (e.g., gender, age, experience, education attainment, and income) of the respondents on safe food-handling behaviors (Nesbitt et al., 2014; Young et al., 2017a, b). Individuals' characteristics are likely to reflect their views of foodsafety issues, thus motivating subsequent responses against the perceived risks. This research claimed that neither gender, age, or education were statistically significant in determining safe food-handling behaviors. The positive impacts of income were stressed contributed to the behaviors of cross-contamination prevention and time-temperature control of foods, while not significant on the rest. Higher-income people tended to underrate food risks (Frewer, 2000), potentially hindering their adoption of safe food-handling behaviors as those shall not be perceived as necessary. However, this study's finding was more likely to align with Dang et al. (2019) that income came with the chance of opting for safe options. The underlying reason could be that poorer individuals tend to have lower knowledge than the richer ones (Nguyen et al., 2018). Another plausible reason might be associated with the negative correlation $(\mathrm{r}=-0.216, \mathrm{p}<0.01)$ between income and the perception of food risks, denoting that the higher-income individual perceives less of food risks caused by animal diseases, which could demotivate their subsequent coping behaviors.

Similarly, having a minor or high-risk member in the family could influence the safe food-handling behaviors of the main food-handlers. Particularly, the positive impact of having a minor on the adequate cooking behavior was detected but nonsignificant on other behaviors. To unfold a feasible explanation, we further ran the Pearson pairwise analysis and found an interesting pattern of the correlation between having a minor and information-seeking $(\mathrm{r}=-0.206, \mathrm{p}<0.01), \mathrm{PBC}(\mathrm{r}=-0.315$, $\mathrm{p}<0.001)$, trust $(\mathrm{r}=0.234, \mathrm{p}<0.01)$, habit $(\mathrm{r}=0.199, \mathrm{p}<0.01)$, and attitude $(\mathrm{r}=0.211, \mathrm{p}<0.01)$. Apparently, a family with minors was likely to trust the information received, have a positive habit of practicing adequate cooking behavior, and reserve a positive attitude toward the handling behavior, but rarely seek safe foodhandling information, and might conduct safe food-handling activities without confidence and comfort. With the support of the magnitude and signs of the impacts of habit $(\beta=0.647)$ and $\mathrm{PBC}(\beta=0.224)$ on the same behavior, we contend that the food handlers, with minors in the family, particularly found it 
comfortable and habitual practicing the behavior of adequate cooking of foods, but not the other behaviors. Nevertheless, having a minor in the family was argued to influence the uptake of safe food choices (Dang et al., 2019). In a similar context in school canteens, experts also suggested the importance of food-handling practices on children's health and that those who prepare food should be well-aware (Santos et al., 2008).

Regarding the original TPB predictors, only PBC and intention were statistically significant, while subjective norm and attitude were not. In line with expectations, the outcomes indicated subjective norm and attitude have no direct relationship with behaviors (Ajzen, 1991) but through intentions. Indeed, a myriad of literature found the positive impacts of these determinants on intentions rather than behaviors (see Mullan et al., 2015; Young et al., 2017a, b, 2019; Ruby et al., 2019)). However, by virtue of the intention-behavior gap, and the given evidence that the original TPB in this study can explain a relatively low proportion of the variance of safe food-handling behaviors, we suggest that future research should stay focus on the actual behavior rather than the intention.

This study also advocated that the contribution of PBC and intention is not consistent in explaining distinct safe food-handling behaviors. Specifically, PBC ( $\beta=0.224)$ made a significant contribution to the behavior of adequate cooking, but not other behaviors. However, in a different context regarding the frequent food-handlers in Australia, the positive impact of PBC was found on the behavior of keeping food at the correct temperature (Mullan et al., 2015). Similarly, the degree of hygienic and safety implementation was found correlated with handlers' perception of the capability of implementing them in the case of food-handlers of fast-food restaurants in France (Kouabenan \& Ngueutsa, 2016). The discrepancy of impacts between models may relate to the difference in at-home food processing culture and habits. Future studies are recommended to investigate this matter across food-safety contexts or countries. In the $\mathrm{TPB}$, the intention is postulated to be the primary determinant of behaviors, and the impacts of other related constructs are indirect through this predictor (Ajzen, 1991). Contrariwise, analogous to the finding of Young et al. (2017b), this paper's outcomes indicated that behavioral intentions are not likely the sole and direct element impacting the safe foodhandling behaviors, and their effects deem dissimilar on specific handling behaviors. In this vein, the statistical significance of intentions on the behaviors of cross-contamination prevention and time-temperature control of foods was found, but not significant on the other two. This sheds light on the third aim of the paper. Maybe it was time for the scientific community to pay heed to the unintentional predictors (e.g., habitual) to bridge the intention-behavior gap, predominantly to predict safe food-handling behaviors.

\section{Conclusion and limitations}

This study serves to answer three objectives. The extended TPB in this study outperformed the original TPB in explaining and predicting safe food-handling behaviors, answering the first goal. For the second one, the disparity of impacts of the additional determinants was confirmed. Lastly, we also corroborated the potential of the multidimensional development of the TPB apart from intention, which was constrained and finite in the intention-behavior relationship. It was also worth noting that, in the extended TPB, habit and info-seeking were consistent and significant determinants across behaviors. Also, the effects of intention on different behaviors were not stable could be because its impact was too generalized as the adoption and degree of adoption for distinct handling practices vary across food handlers. Thus, we fully acknowledge that this is a limitation of this study. Future studies should measure handlers' intentions on specific handling behaviors to investigate the deviation between intentions (if any). Upon completing this paper, we offer the evidence to suggest that there is a need to derail the TPB from its conventional trails away from intentional factors and toward volitional predictors to max out its prediction power for different behaviors. The intention-behavior gap indicates that new volitional predictors (e.g., habit) could be the complementary line to explain the remaining variance left of the motivational factors (e.g., intention). In the light of the majority of studies without the disruption of the TPB in the mentioned way, the research area for this particular need remains humongous. The author also agrees with the recommendation of Mullan et al. (2015) that the SEM approach could be valuable to unravel more insights into the relationships between relevant constructs.

There are several prospective policy implications of this research for the government to improve safe food-handling behaviors. Firstly, there is no 'one size fits all' intervention for (un)safe food-handling behaviors. Food handlers' awareness of food risks needs to be alerted alongside any updates regarding the COVID-19. The targeted family should be of low income and those with minors in the family. There is a necessity to incorporate detailed knowledge regarding the specific type of foodhandling being promoted on the ground of different influences on distinct handling behaviors. General knowledge will not likely be translated into all safe food-handling behaviors. Ncube et al. (2020) recommended that food poisoning can be avoided by training regarding specifically related food risks. To enhance the intervention's effects, the disseminated knowledge should also be diffused under the name of either the Ministry of Health or local health authorities that the food-handlers have confidence in. Pro-active measures of the government against the outbreak of the COVID-19 pandemic have resulted in positive feedbacks and high trust of the consumers. Thus, the government's effort to combat food risks at this point could create the synergy to win back consumers' trust regarding food issues. For that reason, actions should be taken before the opportunity is wasted.

\section{Acknowledgement}

This work was funded by Nong Lam University.

\section{References}

Ajzen, I. (1991). The theory of planned behavior. Organizational Behavior and Human Decision Processes, 50(2), 179-211. http:// dx.doi.org/10.1016/0749-5978(91)90020-T.

Almanza, B. A., Namkung, Y., Ismail, J. A., \& Nelson, D. C. (2007). Clients' safe food-handling knowledge and risk behavior in a homedelivered food program. Journal of the American Dietetic Association, 
107(5), 816-821. http://dx.doi.org/10.1016/j.jada.2007.02.043. PMid:17467379.

Andersen, K. G., Rambaut, A., Lipkin, W. I., Holmes, E. C., \& Garry, R. F. (2020). The proximal origin of SARS-CoV-2. Nature Medicine, 26(4), 450-452. http://dx.doi.org/10.1038/s41591-020-0820-9. PMid:32284615.

Bamgboje-Ayodele, A., Ellis, L., \& Turner, P. (2019). Developing a framework for understanding and enhancing Consumers' Safe food management behaviors - a literature review. Journal of Agricultural \& Food Information, 20(4), 315-343. http://dx.doi.org /10.1080/10496505.2019.1610659.

Bearth, A., Cousin, M. E., \& Siegrist, M. (2014). Poultry consumers' behaviour, risk perception and knowledge related to campylobacteriosis and domestic food safety. Food Control, 44, 166-176. http://dx.doi. org/10.1016/j.foodcont.2014.03.055.

Clayton, D. A., Griffith, C. J., Price, P., \& Peters, A. C. (2002). Food handlers' beliefs and self-reported practices. International Journal of Environmental Health Research, 12(1), 25-39. http://dx.doi. org/10.1080/09603120120110031. PMid:11970813.

Dang, D. H., Pham, T. T., Tran, G. T., Dam, T. H. A., \& Nguyen, T. T. M. (2019). Vietnamese consumers' preferences for traceable food and safety attributes: the case of water spinach. Journal of Asian Business and Economic Studies, 26(S02), 47-70. https://www.doi. org/10.24311/jabes/2019.26.S02.03.

Dang, H. D., \& Tran, G. T. (2020a). Consumers value healthy eating and environmental responsibility: how negative food contexts aid decision-making. Food Science and Technology (Campinas), In press. http://dx.doi.org/10.1590/fst.28120.

Dang, H. D., \& Tran, G. T. (2020b). Explaining consumers' intention for traceable pork regarding animal disease: the role of food safety concern, risk perception, trust, and habit. International Journal of Food Science, 2020, 8831356. http://dx.doi.org/10.1155/2020/8831356. PMid:33178815.

Dang-Xuan, S., Nguyen-Viet, H., Pham-Duc, P., Grace, D., Unger, F., Nguyen-Hai, N., Nguyen-Tien, T., \& Makita, K. (2018). Simulating cross-contamination of cooked pork with salmonella enterica from raw pork through home kitchen preparation in Vietnam. International Journal of Environmental Research and Public Health, 15(10), 2324. http://dx.doi.org/10.3390/ijerph15102324. PMid:30360454.

De Jonge, J., Van Trijp, H., Renes, R. J., \& Frewer, L. J. (2010). Consumer confidence in the safety of food and newspaper coverage of food safety issues: a longitudinal perspective. Risk Analysis, 30(1), 125-142. http://dx.doi.org/10.1111/j.1539-6924.2009.01320.x. PMid:20002892.

Figuié, M., \& Fournier, T. (2008). Avian Influenza in Vietnam: chickenhearted consumers? Risk Analysis, 28(2), 441-451. http://dx.doi. org/10.1111/j.1539-6924.2008.01039.x. PMid:18419660.

Fischhoff, B., Slovic, P., Lichtenstein, S., Read, S., \& Combs, B. (1978). How safe is safe enough? A psychometric study of attitudes towards technological risks and benefits. Policy Sciences, 9(2), 127-152. http:// dx.doi.org/10.1007/BF00143739.

Frewer, L. (2000). Risk perception and risk communication about food safety issues. Nutrition Bulletin, 25(1), 31-33. http://dx.doi. org/10.1046/j.1467-3010.2000.00015.x.

Gstraunthaler, T., \& Day, R. (2008). Avian influenza in the UK: knowledge, risk perception and risk reduction strategies. British Food Journal, 110(3), 260-270. http://dx.doi.org/10.1108/00070700810858673.

Hair, F. J., Black, W., Babin, B., \& Anderson, R. (2010). Multivariate data analysis: a global perspective. New Jersey: Pearson Education.
Han, D. B., \& Choi, J. Y. (2018). Consumers' food safety concern over animal diseases consumer perception of food attributes (pp. 32-51). Boca Raton, FL: CRC Press.

Ifft, J., Roland-Holst, D., \& Zilberman, D. (2009, July 26-28). Valuation of safety-branded and traceable free range chicken in $\mathrm{Ha}$ Noi: Results from a field experiment. In Proceeding of the 2009 Annual Meeting. Milwaukee, Wisconsin: Agricultural and Applied Economics Association.

Kouabenan, D. R., \& Ngueutsa, R. (2016). Control beliefs and engagement in hygienic and safety behaviours: the case of foodborne illness. International Journal of Environmental Health Research, 26(4), 381395. https://doi.org/10.1080/09603123.2015.1119807.

Kuttschreuter, M., Rutsaert, P., Hilverda, F., Regan, A., Barnett, J., \& Verbeke, W. (2014). Seeking information about food-related risks: the contribution of social media. Food Quality and Preference, 37, 10-18. http://dx.doi.org/10.1016/j.foodqual.2014.04.006.

Lo, A. Y., \& Chan, F. (2017). Preparing for flooding in England and Wales: the role of risk perception and the social context in driving individual action. Natural Hazards, 88(1), 367-387. http://dx.doi. org/10.1007/s11069-017-2870-y.

Mullan, B., Allom, V., Sainsbury, K., \& Monds, L. A. (2015). Examining the predictive utility of an extended theory of planned behaviour model in the context of specific individual safe food-handling. Appetite, 90, 91-98. http://dx.doi.org/10.1016/j.appet.2015.02.033. PMid:25728884.

Murray, R., Glass-Kaastra, S., Gardhouse, C., Marshall, B., Ciampa, N., Franklin, K., Hurst, M., Thomas, M. K., \& Nesbitt, A. (2017). Canadian consumer food safety practices and knowledge: Foodbook study. Journal of Food Protection, 80(10), 1711-1718. http://dx.doi. org/10.4315/0362-028X.JFP-17-108. PMid:28906156.

Ncube, F., Kanda, A., Muzeketwa, D., Chiripamberi, V., \& Madondo, M. C. (2020). Risk factors for food poisoning among self-catering university students. International Journal of Environmental Health Research, 1-11. http://dx.doi.org/10.1080/09603123.2020.1723498 . PMid:32013547.

Nesbitt, A., Thomas, M. K., Marshall, B., Snedeker, K., Meleta, K., Watson, B., \& Bienefeld, M. (2014). Baseline for consumer food safety knowledge and behaviour in Canada. Food Control, 38, 157173. http://dx.doi.org/10.1016/j.foodcont.2013.10.010.

Nguyen, A. T. L., Tran, B. X., Le, H. T., Le, X. T. T., Do, K. N., Do, H. T., Vu, G. T., Nguyen, L. H., Latkin, C. A., Ho, C. S. H., \& Ho, R. C. M. (2018). Customers' knowledge, attitude, and practices towards food hygiene and safety standards of handlers in food facilities in Hanoi, Vietnam. International Journal of Environmental Research and Public Health, 15(10), 2101. http://dx.doi.org/10.3390/ijerph15102101. PMid:30257446.

Nguyen, N. V., Tran, L. D., \& Dang, H. D. (2015). Sustainability in pig value chain in Dong Nai province, Vietnam: a viewpoint from social perspective food-safety. Journal of Agricultural Science and Technology, 4, 35-42. http://dx.doi.org/10.6084/m9.figshare.12236237.

Rodríguez-Entrena, M., Salazar-Ordóñez, M., \& Becerra-Alonso, D. (2016). An assessment of the barriers to the consumers' uptake of genetically modified foods: a neural network analysis. Journal of the Science of Food and Agriculture, 96(5), 1548-1555. http://dx.doi. org/10.1002/jsfa.7247. PMid:25959585.

Ruby, G. E., Ungku Zainal Abidin, U. F., Lihan, S., Jambari, N. N., \& Radu, S. (2019). Predicting intention on safe food handling among adult consumers: a cross sectional study in Sibu district, Malaysia. Food Control, 106, 106696. http://dx.doi.org/10.1016/j. foodcont.2019.06.022. 
Santos, M.-J., Nogueira, J. R., Patarata, L., \& Mayan, O. (2008). Knowledge levels of food handlers in Portuguese school canteens and their self-reported behaviour towards food safety. International Journal of Environmental Health Research, 18(6), 387-401. http://dx.doi. org/10.1080/09603120802100212. PMid:19031144.

Scott, E. (2003). Food safety and foodborne disease in 21st century homes. The Canadian Journal of Infectious Diseases, 14(5), 277-280. http://dx.doi.org/10.1155/2003/363984. PMid:18159469.

Slovic, P. (1992). Perception of risk: reflections on the psychometric paradigm. In S. Krimsky, Golding, D., (Eds.), Social theories of risk (pp. 117-152). New York: Praeger.

Spence, M., Stancu, V., Elliott, C. T., \& Dean, M. (2018). Exploring consumer purchase intentions towards traceable minced beef and beef steak using the theory of planned behavior. Food Control, 91, 138-147. http://dx.doi.org/10.1016/j.foodcont.2018.03.035.

Teisl, M. F., Lando, A. M., Levy, A. S., \& Noblet, C. L. (2016). Importance of cohorts in analyzing trends in safe at-home food-handling practices. Food Control, 62, 381-389. http://dx.doi.org/10.1016/j. foodcont.2015.10.040.

Tiozzo, B., Mari, S., Ruzza, M., Crovato, S., \& Ravarotto, L. (2017). Consumers' perceptions of food risks: a snapshot of the Italian Triveneto Area. Appetite, 111, 105-115. http://dx.doi.org/10.1016/j. appet.2016.12.028. PMid:28024884.

Tiozzo, B., Pinto, A., Mascarello, G., Mantovani, C., \& Ravarotto, L. (2019). Which food safety information sources do Italian consumers prefer? Suggestions for the development of effective food risk communication. Journal of Risk Research, 22(8), 1062-1077. http:// dx.doi.org/10.1080/13669877.2018.1440414.

United States Department of Agriculture - USDA. (2013). Washing food: does it promote food safety? Retrieved from https://www.fsis. usda.gov/wps/portal/fsis/topics/food-safety-education/get-answers/ food-safety-fact-sheets/safe-food-handling/washing-food-does-itpromote-food-safety/washing-food

van Doremalen, N., Bushmaker, T., Morris, D. H., Holbrook, M. G., Gamble, A., Williamson, B. N., Tamin, A., Harcourt, J. L., Thornburg, N. J., Gerber, S. I., Lloyd-Smith, J. O., de Wit, E., \& Munster, V. J. (2020). Aerosol and Surface Stability of SARS-CoV-2 as compared with SARS-CoV-1. New England Journal of Medicine, 382(16), 15641567. https://www.doi.org/10.1056/NEJMc2004973.

Young, I., \& Waddell, L. (2016). Barriers and facilitators to safe food handling among consumers: a systematic review and thematic synthesis of qualitative research studies. PLoS One, 11(12), e0167695. http://dx.doi.org/10.1371/journal.pone.0167695. PMid:27907161.

Young, I., Reimer, D., Greig, J., Meldrum, R., Turgeon, P., \& Waddell, L. (2017a). Explaining consumer safe food handling through behaviorchange theories: a systematic review. Foodborne Pathogens and Disease, 14(11), 609-622. http://dx.doi.org/10.1089/fpd.2017.2288. PMid:28719239.

Young, I., Reimer, D., Greig, J., Turgeon, P., Meldrum, R., \& Waddell, L. (2017b). Psychosocial and health-status determinants of safe food handling among consumers: a systematic review and meta-analysis. Food Control, 78, 401-411.http://dx.doi.org/10.1016/j.foodcont.2017.03.013.

Young, I., Thaivalappil, A., Greig, J., Meldrum, R., \& Waddell, L. (2018). Explaining the food safety behaviours of food handlers using theories of behaviour change: a systematic review. International Journal of Environmental Health Research, 28(3), 323-340. http://dx.doi.org/ 10.1080/09603123.2018.1476846. PMid:29852750.

Young, I., Thaivalappil, A., Waddell, L., Meldrum, R., \& Greig, J. (2019). Psychosocial and organizational determinants of safe food handling at retail and food service establishments: a systematic review and meta-analysis. International Journal of Environmental Health Research, 29(4), 371-386. http://dx.doi.org/10.1080/096031 23.2018.1544611. PMid:30409052. 